\title{
The target poly- subject motivation - a means of forming a positive motivation of a child toward learning activity
}

\author{
Semenova Larissa \\ Innovative University Of Eurasia, Pavlodar, Kazakhstan
}

Email address:

Laresa1964@inbox.ru (S. Larissa)

To cite this article:

Semenova Larissa. The Target Poly- Subject Motivation - a Means of Forming a Positive Motivation of a Child Toward Learning Activity, International Journal of Secondary Education. Vol. 1, No. 1, 2013, pp. 1-3. doi: 10.11648/j.ijsedu.20130101.11

\begin{abstract}
In this article suggests ways to improve the efficiency of the educational process. The author gives the definition of the target poly-subjective motivation. The author also conducted an analysis of the dependence of the level of motivation of students from the components of the target poly-centered motivation.
\end{abstract}

Keywords: The Target Poly-Subjective Motivation, The Motivation Of The Student, The Learning Process

\section{Introduction}

School - is a pedagogical system that is created by society and changing with the renewal of society and changes in its social order.

Development of the school without new ideas is impossible, i.e. innovation process is necessary.

In the conditions of humanization and democratization of education a director and a teacher, a teacher and a student change, interact and together participate in the renewal of school life.

It is common knowledge that the student cannot be successfully taught, if he is not motivated to acquire knowledge, i.e. takes the study and knowledge indifferently without interest, without realizing the need for them.

In order to let a student be consciously involved in work, it is necessary that the tasks given to him in the course of learning activities would be internally recognized and taken, i.e. that they would acquire significance for the student.

Thus, the task of school is to form and develop the child's perceived positive motivation for learning activities. Therefore, in the future we will talk about the learning motivation.

The formation of any personality trait is not possible without a detailed study of its nature and the factors influencing this process. The study of motivation reveals an opportunity to identify prospects and zones of proximal development of a student. Consequently, there is a fairly clear idea of the field of student motivation and methods of stimulating his learning motivation.

\section{The Target Motivation of Pupils in the Educational Process}

A motive is a motivating factor in a particular activity. The realization of motives depends on the set goal. It is obvious that the target level will be directly linked to the level of motivation. In accordance with the content of our research we are interested in educational - cognitive purposes and, therefore, learning- cognitive motivation of students.

As the purpose of learning motivation is to encourage students to develop their skills for more intensive and productive work in modern conditions for the achievement of learning purposes, the teacher has to practice modern models of motivation to allow students to achieve high results in the achievement of set purposes.

During training, the motivational sphere of a student is under the constant influence of both the external and internal environment. In active learning activities the child is mostly under the guidance of teachers.

Working with students, the teacher must learn to understand the mechanism of their actions and motivation of behavior.

To solve this problem it is necessary to find out the components of student's motivation and to answer the question about the factors that influence its occurrence.

Motive is motivation to achieve goals.

Two variants are possible:

1. The student understands why it is necessary to learn, but it is still not an incentive for him to be actively engaged in learning activities. 
2. In specific conditions the motives that are understood and accepted by the student internally, become really active, that is, induce to action.

Learning motivation is polynomial, because it consists of a group of motives: cognitive, emotional, internal (student's position), external (achievements, awards), etc. Consequently, there are a number of factors affecting its formation. The teacher should constantly bear in mind that each student is encouraged by several motives, as learning activity always is poly-motivated.

Learning activities are always permeated with social interaction, communication of a student with others.

The same behavior of a student during learning process may be induced by different motives, and therefore have different significance for the student.

The above leads to the conclusion that in order to improve the efficiency of the educational process it is necessary to form the target motivation of a child to learn. And what is it formed of? What and who can significantly influence its formation?

The study of this question in psychology suggests that the development of motives for learning goes two ways:

1. Through the assimilation of social meaning of learning by students.

2. Through the student's learning activity itself which should interest him. [1]

One of the conditions that motivates the child to achieve the goals, and, therefore, influences the occurrence of motivation is the pedagogical support of the child, the purpose of which is to remove the barriers that hinder the student's progress in achieving success in the process of education, training and development.

O.S. Gazman [2] and T.V. Anokhina [3] developed the basic principles of providing pedagogical support:

- agreement of a child for care and support;

- support on the available forces and the potentialities of the individual;

- belief in these potentialities;

- focus on a child's ability to overcome obstacles on his own;

- consistency, cooperation, assistance;

- privacy (anonymity);

- goodwill, no assesment;

- safety, protection of health, rights and human dignity;

- implementation of the principle of "do not harm";

- reflective and analytical approach to the process and the result.

\section{The Target Poly-Subject Motivation}

As the pedagogical support should be implemented not only by the teachers, but also by the parents, as educating a teenager is determined by a social-psychological climate in the family, psychological and pedagogical culture of parents, a moral direction of a family as a social institution, then, in our opinion, it is necessary to the above-mentioned principles to add one more - providing target poly- subjective motivation.

Under a target poly-subjective motivation we suggest to understand a complex system, formed by motives, objectives, tasks of actors involved in training, education, which runs, directs and supports the efforts of a child directed at implementing learning activities.

In other words it is the combination of motivations of each subject with a single goal, in solving by each subject their own tasks.

In the form of a mathematical formula we can show the dependence of the on performance of target poly-subjective motivation as follows:

$$
\mathrm{LSM} \rightarrow \mathrm{PTPSM}=\mathrm{LSM}+\mathrm{TTM}+\mathrm{TPM} \rightarrow \mathrm{CT}
$$

where PTPSM - performance of target poly-subjective motivation, LSM - level of student's motivation, TTM target teacher's motivation, TPM - target parents' motivation, $\mathrm{CT}$ - common target.

If we analyze this formula, from a mathematical point of view, we see that the absence of one of the components reduces PTPSM, and, consequently, LSM, which in its turn reduces the chances of achieving a full $\mathrm{CT}$.

Thus, it is clear that the effective formation and development of the child's positive motivation for learning activities require targeted poly-subjective motivation.

Based on the foregoing, it can be concluded that it is necessary to consider more carefully the components of this formula, i.e. TTM - target teacher's motivation, TPM target parents' motivation and find mechanisms to develop and improve the given components.

The first component is the target teacher motivation.

The teacher himself must be internally motivated for the success of teaching students. A teacher with a high motivation is an individual with a strong love for the teaching profession and interest in the result of its performance as well as, what we think is important, a high level of professionalism and self-confidence.

Learning is regarded as active activity of students on acquiring knowledge, including methods of independent learning. Educational activity of the student is always joint (with a teacher, with students). Therefore, a student always (explicitly or implicitly) uses the methods of learning activities given to him by the teacher.

Therefore, well - organized work by a teacher may encourage the student to acquire and master knowledge.

We agree with A.K. Markova's opinion that the teacher should take into account poly-motivation of teaching. She proposed methods of teacher's studying of students' learning motivation, the most practical of which are the following:

- monitoring the students' behavior during class and outside the classroom, academic, social useful, organizational and other activities, the nature of students' communication (results of these observations are recorded in the teachers' diaries, teacher');

- use of a number of specially selected situations (they can be called experimental teaching situations) that can be 
included in the natural course of the educational process in form of "control work", in the form of tasks of a supervising teacher in the classroom hour;

- personal interview with the student assuming the teacher's direct and indirect questions about the motives, the meaning, purposes of learning for the student;

- questionnaire survey, helping to collect abundant material rather quickly in several classes, schools on students' attitude to learning. [4]

Typology of motives of learning can be examined by the test "Ladder of motives" (A.I. Bozhovich, I.K. Markova) [5]

The study of motivation of each student, in our opinion, should also be poly-subjective, that is, it is necessary to compare the characteristics given to the student not by one, but several teachers, parents, the supervising teacher.

One of the factors that contribute to motivating students is a cognitive interest. Cognitive interest is a special elective direction of the individual in learning process. L.S. Vygotsky emphasized that the interest is the natural engine of behavior, it is a true expression of the instinctive intention. [6]

In many studies the cognitive interest as a motive of learning is considered in the mutual relations with other motives. C. J. Rubinstein, G.I. Shchukin, F.K. Savina and others view the learning process as the strongest motive of learning. According to studies by G.I. Shchukina cognitive interest appears among other motives as central. " At the high level of development, repeating, becoming stronger in many situations, the interest plays the role of the leading motive of learning while the other motives (duty, responsibility, professional intentions), coinciding with the goal of the forthcoming activity, determining its meaning, lead the activity itself to the interest," - F.K. Savina claims [7].

G. I. Shchukina [8] has singled out the features that distinguish cognitive interest from other motives for learning:

Cognitive interest - the most preferred motive by the students among other motives of learning.

Cognitive interest as the motive of learning "earlier and more recognized by the students."

Cognitive interest as a motive has "disinterested nature."

Cognitive interest, "creating the internal environment of development, changes considerably the power of the activity, influences the character of the course and its outcome."

Cognitive interest is growing among other motives, and interacts with them.

\section{Conclusion}

Motivation of achieving a particular result begins to develop in children as early as in the preschool years. The attitude to learning created by education and parental example mostly develops just before entering the first grade.

Therefore, it is necessary to continue to study the parents' target motivation regarding their children's educational activities.

\section{References}

[1] G. I. Shchukina Activization of cognitive activity of students in the learning process. - M.: Provsveshcheniye, 1979. -160 p.

[2] Gazman O.S. "Pedagogical support of children in education as an innovative problem" New values of education: ten concepts and essays. Issue 3. / editor N.B. Krylova. - M., 1995.

[3] Anokhina T.V. "Pedagogical support as reality of contemporary education" New values of education. Issue 6 - M. 1996.

[4] Markova A.K. Formation of motivation of learning in school age: Textbook for teachers. - M.: Prosvescheniye, 1983. $-96 \mathrm{p}$.

[5] N.L. Fetiskin, V.V. Kozlov, G.M.Mainulov Social and psychological diagnostics of the development of personality and small groups. - M, 2002. P.107.

[6] L.S. Vygotsky Pedagogical psychology. - M.: Prosveshcheniye, 1996. $-278 \mathrm{p}$.

[7] F.K.Savina Formation of students' cognitive interests in conditions of school reforms: Textbook for a special course. - Volgograd: VSPI named after A.S. Serafimovich 1989. $67 \mathrm{p}$

[8] G.I. Shchukina Methods of study and formation of students cognitive interests. Pedagogics,1971.- p. 352-358. 